\title{
ANALISIS KONDUKTIVITAS DAN TERMAL PADA POLIMER ELEKTROLIT DARI KITOSAN/PVA/GLISEROL/LiCIO 4 UNTUK APLIKASI BATERAI ION LITIUM
}

\author{
Nurhadini ${ }^{1}$, Verry Andre Fabiani ${ }^{1}$, Megawati Ayu Putri $^{1}$, Iin Lestari ${ }^{1}$ \\ Jurusan Kimia, Fakultas Teknik, Universitas Bangka Belitung, Kampus Terpadu Balunijuk \\ Email: nurhadini88@gmail.com
}

\begin{abstract}
ABSTRAK
Penggunaan polimer ramah lingkungan merupakan tantangan bagi industri baterai ion litium saat ini dikarenakan sifatnya yang mudah terbiodegradasi menjadi keunggulan polimer alam seperti kitosan dengan bahan baku dari alam yang melimpah. Komposisi polimer elektrolit dalam penelitian ini terdiri atas kitosan, PVA, gliserol yang didopan dengan $\mathrm{LiClO}_{4}$. Penelitian ini bertujuan untuk menganalisis sifat konduktivitas dan termal dari polimer elektrolit kitosan/PVA/gliserol/LiClO 4 . Pembuatan polimer elektrolit ini menggunakan metode casting. Peningkatan massa kitosan dalam komposisi polimer elektrolit menyebabkan adanya peningkatan intensitas pada bilangan gelombang $1718 \mathrm{~cm}^{-1}$ dan peningkatan intensitas serapan pada bilngangan gelombang $1271 \mathrm{~cm}^{-1}$ dengan masing-masing puncak serapan tersebut adalah gugus fungsi dari $\mathrm{C}=\mathrm{O}$ dan gugus fungsi $\mathrm{C}-\mathrm{O}$. Berdasarkan data konduktivitas menunjukkan bahwa komposisi 70/30/20/20 (kitosan /PVA/Gliserol/LiClO $_{4}$ ) memiliki konduktivitas tertinggi sebesar $4,8 \times 10^{-5} \mathrm{~S} / \mathrm{cm}$. Hasil kurva TGA menunjukkan stabilitas termal komposisi polimer elektrolit hingga $210^{\circ} \mathrm{C}$ dan peningkatan jumlah kitosan dalam polimer elektrolit menurunkan kestabilan termal. Polimer elektrolit dari kitosan/PVA/Gliserol/LiClO ${ }_{4}$ dapat diaplikasikan untuk baterai ion litium berdasarkan analisis konduktivitas ionik dan kestabilan termal.
\end{abstract}

Kata Kunci: baterai ion litium, kitosan, konduktivitas, termal, polimer elektrolit

\begin{abstract}
The use of environmentally friendly polymers is a challenge for the lithium-ion batteries industry today because its biodegradable nature is an advantage of natural polymers such as chitosan with abundant raw materials from nature. The polymer electrolyte composition in this study consisted of chitosan, PVA, glycerol doped with $\mathrm{LiClO}_{4}$. This study aims to analyze the conductivity and thermal properties of the polymer electrolyte chitosan/PVA/Glycerol/LiClO 4 . The polymer electrolyte was made using a casting method. The increasing of the chitosan mass in the polymer electrolyte composition led to an increase in intensity at the wave number $1718 \mathrm{~cm}^{-}$ 1 and an increase in absorption intensity at the wavenumber of $1271 \mathrm{~cm}^{-1}$ with absorption peaks being a functional group of $\mathrm{C}=\mathrm{O}$ and $\mathrm{C}-\mathrm{O}$ respectively. Based on the conductivity data, it showed that the composition of $70 / 30 / 20 / 20$ (chitosan/PVA/Glycerol/ $/ \mathrm{LiClO}_{4}$ ) had the highest conductivity of $4.8 \times 10^{-5} \mathrm{~S} / \mathrm{cm}$. The results of the TGA curve illustrated that polymer electrolyte had thermal stability until $210^{\circ} \mathrm{C}$ and the increasing amount of chitosan of polymer electrolyte decreased thermal stability. Polymer electrolyte chitosan/PVA/Glycerol/LiClO ${ }_{4}$ is suitable for lithium-ion batteries based on ionic conductivity and thermal stability.
\end{abstract}

Keyword: lithium-ion batties, chitosan, conductivity, thermal, polymer electrolyte

\section{PENDAHULUAN}

Baterai merupakan sumber penyimpan energi dengan prinsip elektrokimia yang mengkonversi energi kimia menjadi energi listrik (Hadiyanti dkk., 2018). Seperti telah diketahui bahwa baterai litium merupakan komponen penting pada berbagai peralatan elektronik yang digunakan manusia saat ini seperti laptop, handphone dan gadget lainnya.
Penggunaan baterai dirasa sangat penting untuk kemajuan teknologi kedepannya sehingga inovasi teknologi mengenai baterai perlu dikembangkan lebih lanjut. Namun limbah baterai tersebut akan merusak lingkungan dan sangat berbahaya jika tidak ditangani lebih lanjut. Penggunaan membran polimer elektrolit dianggap lebih aman, praktis, memiliki stabilitas kimia dan termal yang baik, konduktivitas proton yang tinggi, berbiaya rendah, sumber 
bahan baku yang melimpah dan dapat dibentuk dalam ukuran yang kecil menyerupai lapisan tipis (Gray \& Armand, 1999; Rahmawati \& Gonggo, 2013).

Pada baterai litium, ion litium tergabung ke dalam matriks polimer elektrolit yang merupakan polimer sintetik dan tidak ramah lingkungan, yang umumnya menggunakan PEO (Rosero dkk., 2019).. Penggunaan polimer ramah lingkungan merupakan tantangan bagi industri baterai saat ini, sifatnya yang mudah terbiodegradasi menjadi keunggulan polimer alam seperti kitosan. Bahan baku kitosan sangat melimpah di alam sehingga mudah diperoleh dan memiliki stabiltas termal yang tinggi, disisi lain adanya gugus amino dan gugus hidroksil pada kitosan berpotensi untuk dimodifikasi menghasilkan material bermuatan pada pembuatan membran polimer elektrolit(Yulianti dkk., 2013; Jin dkk., 2004; Riyanto dkk., 2011).

Polimer elektrolit dalam penelitian ini tersusun kitosan dengan penambahan agen pengarah struktur berupa semi interpenetrating polymer network (semi-IPN) yaitu poli (vinil alkohol) (PVA) dengan sifat mekanik yang baik (Hassan \& Peppas, 2000). PVA dapat membentuk film yang stabil dengan kristalinitas yang rendah (Zhang et al., 2007). Pada penelitian sebelumnya, kajian mengenai konduktivitas ion pada polimer elektrolit yang tersusun atas $70 \%$ $\begin{array}{llll}\text { kitosan/PVA (90/10) dengan } & 30 \% & \mathrm{LiClO}_{4}\end{array}$ mencapai $4,57 \times 10^{-3} \mathrm{~S} / \mathrm{cm}$ dan memiliki kestabilan termal diatas $150{ }^{\circ} \mathrm{C}$ (Novitasari \& Gonggo, 2016). Adanya penambahan gliserol meningkatkan nilai konduktivitas sementara garam $\mathrm{LiClO}_{4}$ berperan sebagai sumber ion (Alves dkk., 2016; Kadir dkk., 2010). Komposisi polimer penelitian ini menggunakan kitosan/PVA/Gliserol/ $/ \mathrm{LiClO}_{4}$ yang diharapkan yang dapat diaplikasi baterai ion litium.

\section{BAHAN DAN METODE}

Bahan-bahan yang digunakan dalam penelitian ini adalah asam asetat glasial, kitosan, litium perklorat diperoleh dari Merck (Darmstadt, Germany). Sedangkan polivinilasetat (PVA) dan gliserol berkualifikasi teknis.

\section{Sintesis membran polimer elektrolit}

Sejumlah kitosan dilarutkan dalam 2\% asam asetat glasial sebanyak $20 \mathrm{~mL}$ dan pada gelas kimia yang lain dilarutkan PVA dalam $20 \mathrm{~mL}$ akuades dengan total massa polimer sebanyak 0,4 gram. Variasi komposisi kitosan-PVA (\% b/b) yaitu 10/90; 30/70; 50/50; 70/30; dan 90/10. Kemudian masing-masing larutan dicampur dan diaduk dengan pengaduk magnet selama 24 jam hingga homogen. Campuran tersebut dimasukkan masing-masing sebanyak 20\% gliserol (b/b) dan 20\% (b/b) $\mathrm{LiClO}_{4}$ dari total massa polimer. Komposisi total polimer elekrolit (kitosan/PVA/Gliserol/ $\mathrm{LiClO}_{4}$ ) yang digunakan adalah 10/90/20/20; 30/70/20/20; 50/50/20/20; 70/30/20/20; dan 90/10/20/20 (b/b). Setelah membentuk campuran yang homogen, campuran kemudian di-casting dalam plat/wadah akrilik. Kemudian pelarutnya diuapkan selama seminggu pada temperatur kamar dan sehingga terbentuk lapisan tipis polimer elektrolit.

\section{Analisis membran polimer elektrolit}

$\begin{array}{ccr}\text { terbentuk } & \begin{array}{c}\text { polimer } \\ \text { dari }\end{array} & \begin{array}{r}\text { elekrolit yanpuran } \\ \text { campran }\end{array}\end{array}$ kitosan/PVA/gliserol/ $/ \mathrm{LiClO}_{4} \quad$ dilakukan serangkaian karakterisasi meliputi analisis FTIR untuk mengidentifikasi gugus fungsinya, analisis konduktivitas untuk mengetahui kemampuan menghantarkan ion dan analisis termal untuk mengetahui kestabilan termal

\section{HASIL DAN PEMBAHASAN}

\section{Analisis gugus fungsi}

Spektrum

kitosan/PVA/Gliserol/LiClO ${ }_{4}$ menujukkan adanya gugus fungsi yang teridentifikasi pada Gambar 1a dan 1b. Polimer elektrolit memiliki serapan yang mirip pada semua komposisi. Peningkatan kitosan pada komposisi polimer elektrolit $\quad(70 / 30 / 20 / 20 ; \quad 90 / 10 / 20 / 20)$ menyebabkan adanya muncul puncak serapan pada bilangan gelombang $1718 \mathrm{~cm}^{-1}$ dan peningkatan intensitas serapan pada bilangan gelombang $1271 \mathrm{~cm}^{-1}$. Masing-masing puncak serapan tersebut adalah gugus fungsi dari $\mathrm{C}=\mathrm{O}$ dan gugus fungsi C-O yang berasal dari kitosan. 


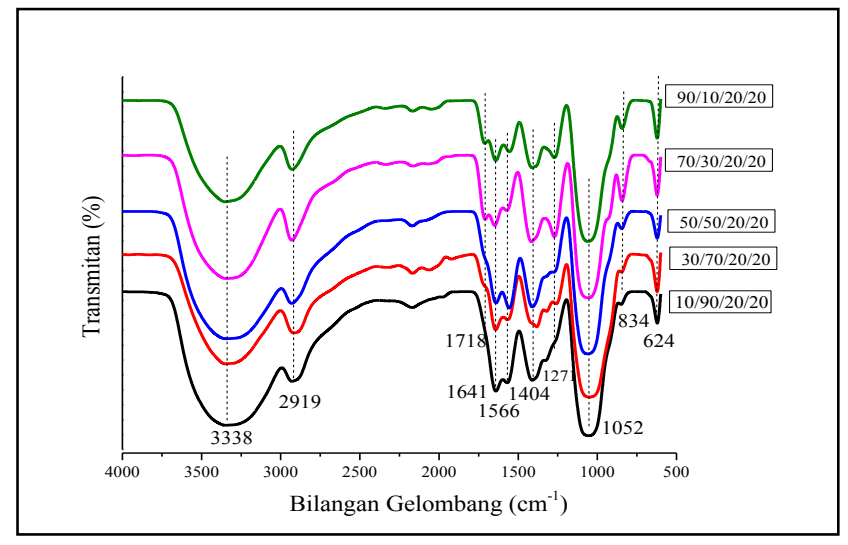

Gambar 1. (a) Spektra ATR-FTIR polimer elektrolit kitosan/PVA/gliserol/ $/ \mathrm{LiClO}_{4}$

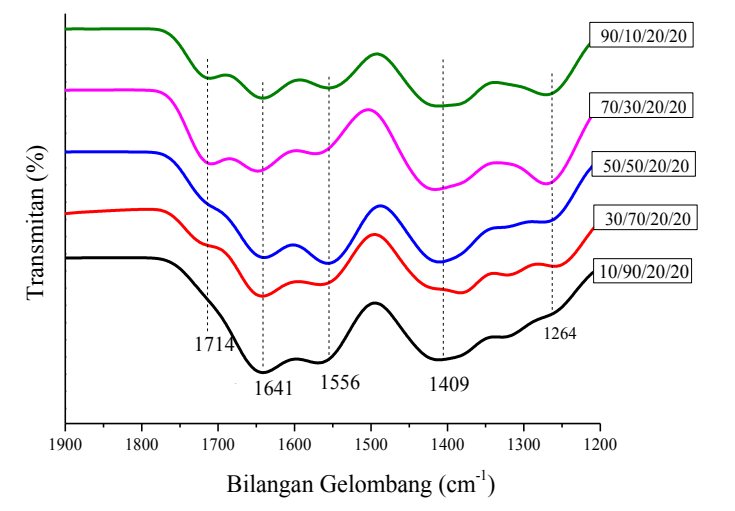

Gambar 1. (b) Perbesaran spektra ATR-FTIR polimer elektrolit kitosan/PVA/gliserol/LiClO 4 pada bilangan gelombang $1700 \mathrm{~cm}^{-1}$ hinga $1200 \mathrm{~cm}^{-1}$

Gugus-gugus fungsi lain yang teridentifikasi adalah gugus fungsi $-\mathrm{OH}$ pada bilangan gelombang $3338 \mathrm{~cm}^{-1}$. Pita serapan pada bilangan gelombang $2919 \mathrm{~cm}^{-1}$ merupakan gugus fungsi $\mathrm{C}-\mathrm{H}$ dari alkil. Pita serapan pada bilangan gelombang $1641 \mathrm{~cm}^{-1}$ merupakan vibrasi ulur dari amida $\mathrm{C}=\mathrm{O}$ dan puncak pada $1566 \mathrm{~cm}^{-1}$ merupakan deformasi dari amida primer. Pita serapan pada bilangan gelombang $1078 \mathrm{~cm}^{-1}$ merupakan vibrasi ulur alkohol primer. Pita serapan pada bilangan gelombang $834 \mathrm{~cm}^{-1}$ dan $624 \mathrm{~cm}^{-1}$ merupakan serapan dari gugus fungsi $\mathrm{ClO}_{4}^{-}$(Gonggo dkk., 2017; Pratiwi, 2018; Yulianti dkk., 2015).

\section{Analisis konduktivitas}

Konduktivitas ionik merupakan komponen yang penting dalam pertimbangan sintesis polimer elektrolit. Hal ini berkaitan dengan kemampuan membran polimer elektrolit tersebut menghantarkan ion litium dari satu ke elektroda lainnya sehingga polimer elektrolit memiliki konduktivitas ionik yang tinggi. Berikut adalah tabel nilai kondukvitas komposisi kitosan/PVA/Gliserol $/ \mathrm{LiClO}_{4}$.

Tabel 1. Konduktivitas $\left(\sigma_{\mathrm{ac}}\right)$ polimer elektrolit komposisi kitosan/PVA/gliserol/ $\mathrm{LiClO}_{4}$

\begin{tabular}{cc} 
Komposisi & $\begin{array}{c}\text { Konduktivitas }\left(\sigma_{\mathrm{ac}}\right) \\
(\mathrm{S} / \mathrm{cm})\end{array}$ \\
\hline $10 / 90 / 20 / 20$ & $2,01 \times 10^{-7}$ \\
$30 / 70 / 20 / 20$ & $2,52 \times 10^{-6}$ \\
$50 / 50 / 20 / 20$ & $8,62 \times 10^{-6}$ \\
$70 / 30 / 20 / 20$ & $4,8 \times 10^{-5}$ \\
$90 / 10 / 20 / 20$ & $4,23 \times 10^{-5}$ \\
\hline
\end{tabular}


Tabel 1. terlihat bahwa nilai konduktivitas tergantung dari komposisi yang digunakan. Konduktivitas ac tertinggi diperoleh pada komposisi polimer elektrolit kitosan/PVA/gliserol/LiClO 4 yaitu $70 / 30 / 20 / 20$ sebesar $4,8 \times 10^{-5} \mathrm{~S} / \mathrm{cm}$. Nilai konduktivitas tertinggi pada komposisi tersebut memenuhi untuk diaplikasikan sebagai polimer elektrolit di baterai ion litium $\left(10^{-7}-10^{-3} \Omega^{-1} \mathrm{~cm}^{-1}\right)$ (Hirankumar, et al., 2004; Hariyawati, et al., 2019). Peningkatan nilai konduktivitas menunjukkan adanya interaksi antara ion $\mathrm{Li}^{+}$dengan gugus $\mathrm{OH}$ dari PVA dan $\mathrm{NH}_{2}$ dari kitosan Gugus-gugus ini bertindak sebagai hoping sites untuk ion $\mathrm{Li}^{+}$ dapat bermigrasi pada campuran polimer elektrolit. Konduktivitas meningkat seiring dengan kemudahan ion $\mathrm{Li}^{+}$bermigrasi dalam polimer elektrolit (Chatterjee, dkk., 2015; Rathod dkk., 2014).

\section{Kestabilan termal}

Kestabilan termal dianalisis melalui TGA yang bertujuan untuk mengetahui dekomposisi polimer elektrolit terhadap temperatur. Kestabilan termal pada polimer elektolit merupakan salah satu parameter yang penting untuk memastikan keamanan dalam penggunaan baterai (Long dkk., 2016). Gambar 2 adalah kurva TGA polimer elektrolit pada kitosan/PVA/gliserol/ $/ \mathrm{LiClO}_{4}$ berbagai komposisi.

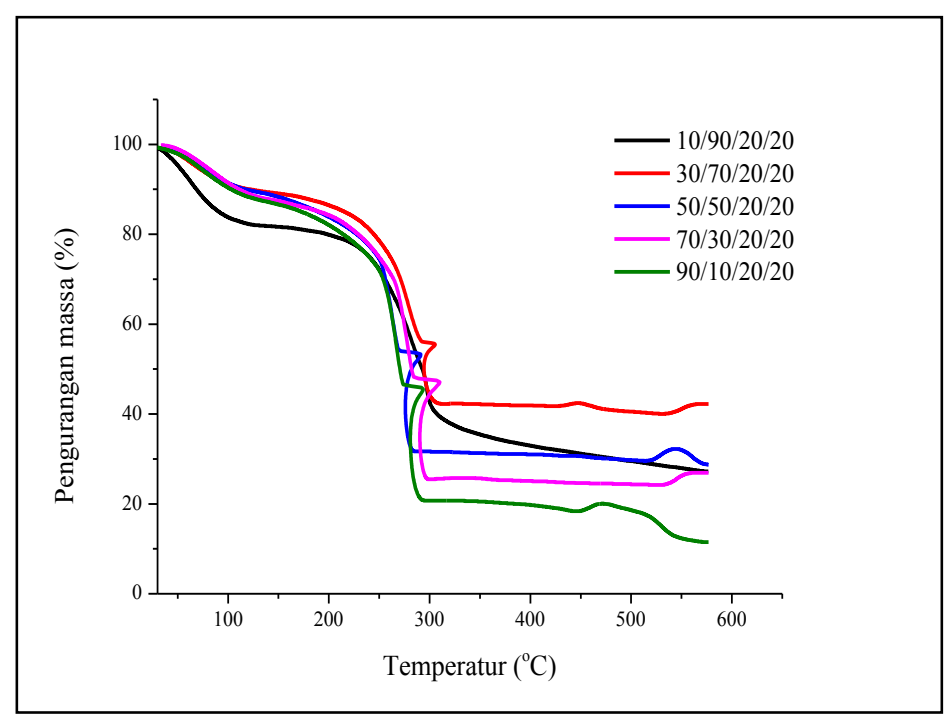

Gambar 2. Kurva TGA kitosan/PVA/gliserol pada berbagai komposisi

\begin{abstract}
Berdasarkan Gambar 2, kestabilan termal polimer elektrolit kitosan/PVA/gliserol/ $/ \mathrm{LiClO}_{4}$ diketahui hingga $210{ }^{\circ} \mathrm{C}$. Penelitian Yusof dkk (2013) pada polimer elektrolit PVA-kitosan dengan penambahan $\mathrm{NH}_{4} \mathrm{Br}$ kestabilan termal diperoleh hingga $260^{\circ} \mathrm{C}$. Pada umumnya suhu operasional baterai ion litium adalah 20-60 ${ }^{\circ} \mathrm{C}$ sehingga polimer elektrolit kitosan/PVA/gliserol/ $/ \mathrm{LiClO}_{4} \quad$ tersebut memungkinkan diaplikasikan pada baterai ion litium. Peningkatan jumlah kitosan dalam polimer elektrolit menyebabkan polimer elektrolit menjadi lebih mudah terdegradasi yang ditandai dengan pengurangan massa yang lebih besar. Pada temperatur $30-100{ }^{\circ} \mathrm{C}$
\end{abstract}

kehilangan massa sebesar $12 \%$ hingga $18 \%$ mengindikasikan kehilangan air dan residu dari asam asetat. Pada temperatur $120-300{ }^{\circ} \mathrm{C}$ terjadi pengurangan massa $40 \%$ hingga $67 \%$. Pengurangan massa terbesar mengindikasikan bahwa polimer elektrolit sudah mulai terdegradasi dengan adanya pemutusan ikatan intermolekular dan struktur molekul (Yusof, dkk., 2014; Riyanto dkk., 2011).

\section{KESIMPULAN}

Berdasarkan analisis gugus fungsi menggunakan ATR-FTIR menunjukkan bahwa peningkatan jumlah kitosan dalam polimer elektrolit meningkatan intensitas 
serapan pada gugus $\mathrm{C}=\mathrm{O}$ dan $\mathrm{C}-\mathrm{O}$ yang berasal dari kitosan. Berdasarkan analisis konduktivitas peningkatan kitosan dalam komposisi polimer elektrolit dapat meningkatkan nilai konduktivitas hingga 4,8 $\mathrm{x} \quad 10^{-5} \quad \mathrm{~S} / \mathrm{cm}$ dengan komposisi kitosan/PVA/gliserol/ $/ \mathrm{LiClO}_{4} \quad$ yaitu 70/30/20/20. Hasil TGA menujukkan bahwa kestabilan termal hingga $210^{\circ} \mathrm{C}$ dan peningkatan jumlah kitosan dalam polimer elektrolit menyebabkan kestabilan termal berkurang.

\section{UCAPAN TERIMAKASIH}

Penulis mengucapkan terima kasih kepada Kementerian Riset dan Teknologi/Badan Riset dan Inovasi Nasional atas didanainya Penelitian Dosen Pemula Tahun 2020.

\section{DAFTAR PUSTAKA}

Alves, R.L.S., Sentanin, F., Sabandini, R.C., Pawlicka, A. \& Silva, M.M. 2016. Influence of cerium triflate and glycerol on electrochemical performance of chitosan electrolytes for electrochromic devices, Electrochimica Acta, 217, 108-116.

Chatterjee, B., Kulshrestha, N. \& Gupta, P.N. 2015. Preparation and characterization of Lithium ion conducting solid polymer electrolytes from biodegradable polymers starch and PVA, International Journal of Engineering Research and Applications, 5(6), 116-131.

Gonggo, S. T., Diah, A.W.M. \& Lateene, R. 2017. Pengaruh kaolin terhadap membran blend kitosan polivinil Alkohol-Litium sebagai membran elektrolit untuk aplikasi baterai ion Litium, Jurnal Akademika Kimia. 6(1), 55-64.

Gray, F., \& Armand, M. 1999. Polymer electrolytes. handbook of battery materials. New York: Wiley-VCH.

Hariyawati, N.K., Saraswati, L.P.A. \& Arcana, I.M. 2019. Properties of polymer electrolytes based on chitosan/poly(vinyl alcohol) for lithium battery application, American Journal of Engineering Research, 8(4), 135143.
Hassan, C.M. \& Peppas, N.A. 2000. Structure and applications of poly (vinyl alcohol) hydrogels produced by conventional crosslinking or by freezing/thawing methods, Advances in Polymer Science.153(9), 37-65.

Hirankumar, G., Selvasekarapandian, S., Bhuvaneshwari, M.S., Baskaran, R., \& Vijayakumar M.S. 2004. AC impedance studies on proton conducting polymer electrolyte complexes $\quad\left(\mathrm{PVA}-\mathrm{CH}_{3} \mathrm{COONH}_{4}\right)$, Ionics. 10(1), 135-138.

Jin, J., Song, M. \& Hourston, D.J. 2004. Novel chitosan-based films cross linked by genipin with improved physical properties, Biomacromolecules. 5(1), 162-168.

Kadir, M.F.Z., Majid, S.R. \& Arof, A.K. 2010. Plasticized chitosan-PVA blend polymer electrolyte based proton battery, Electrochimica Acta, 55(4), 1475-1482.

Long, L., Wang, H., Xiao, M. \& Meng, Y. 2016. Polymer electrolytes for lithium polymer batteries. Journal of Materials Chemistry A. 55(4), 10038-10069.

Novitasari, R. \& Gonggo, S.T., 2016. Pengaruh silika terhadap membran blend kitosan-polivinil alkohol-litium sebagai membran elektrolit baterai ion Litium, Jurnal Kimia Akademika. 5(1), 44-49.

Pratiwi, D.E. 2018. Sintesis membran elektrolit padat berbahan dasar kitosan, Jurnal Sainsmat, 7(2), 86-91.

Rahmawati, S. \& Gonggo, S. 2013. Sintesis membran elektrolit kitosan untuk aplikasi ion litium, Prosiding. Seminar Nasional Sains dan Matematika II.C07.

Rathod, S.G., Bhajantri, R.F., Ravindrachary, V. \& Sheela, T. 2014. Ionic conductivity and dielectric studies of $\mathrm{LiClO}_{4}$ doped poly (vinylalcohol)(PVA)/chitosan(CS) composites, Journal of Advamce Dielectrics. 4(4), 1-7.

Riyanto, B., Maddu, A. \& Dewi, R.S. 2011. Baterai cerdas dari elektrolit polimer kitosan-PVA dengan penambahan ammonium nitrat, Jurnal Pengolahan Hasil Perikanan Indonesia, 14(2), 7077.

Rosero, M.I.D., Meneses, N.M.J. \& Kaffure, 
R.U. 2019. Thermal properties of composite polymer electrolytes poly(ethylene oxide)/sodium trifluoroacetate/aluminum oxide $(\mathrm{PEO})_{10} \mathrm{CF}_{3} \mathrm{COONa}+\mathrm{x}$ wt. $\% \mathrm{Al}_{2} \mathrm{O}_{3}$, Materials. 12(9), 1464.

Yulianti, E., Sudaryanto \& Ginting, J. 2015. Pengaruh penambahan garam-garam lithium terhadap sifat elektrolit padat polimer berbasis kitosan, Jurnal Sains Materi Indonesia. 16(3), 133-138.
Yusof, Y.M., Illias, H.A. \& Kadir, M.F.Z. 2014. Incorporation of $\mathrm{NH}_{4} \mathrm{Br}$ in $\mathrm{PVA}-$ chitosan blend-based polymer electrolyte and its effect on the conductivity and other electrical properties, Ionics. 20(3), 1235-1245

Zhang, Y., Huang, X. \& Duan, B. 2007. Preparation of electrospun chitosan / poly (vinyl alcohol) membranes, Colloid Polymer Science. 285(4), 855863. 